\title{
CULTIVO DO CRAMBE: POTENCIAL PARA PRODUÇÃO DE BIODIESEL ${ }^{1}$
}

\author{
Michael Feroldi ${ }^{2}$, Paulo André Cremonez ${ }^{3}$, Armin Feiden ${ }^{4}$, Eduardo de Rossi ${ }^{5}$, William Cezar Nadaleti ${ }^{6}$, \\ Jonathas Antonelli ${ }^{7}$
}

${ }^{1}$ Aceito para publicação, $1^{\circ}$ trimestre de 2013.

${ }^{2}$ Curso Superior de Tecnologia em Biocombustíveis, Universidade Federal do Paraná, Palotina-PR.

${ }^{3}$ Mestrado em Energia na Agricultura, Universidade Estadual do Oeste do Paraná, Cascavel-PR.

${ }^{4}$ Dr.; Zootecnista, Engenheiro Agrônomo; Professor do Centro de Ciências Agrárias da Universidade Estadual do Oeste do Paraná, UNIOESTE, Campus Marechal Cândido Rondon.

${ }^{5}$ Mestrado em Energia na Agricultura, Universidade Estadual do Oeste do Paraná, Cascavel-PR.

${ }^{6}$ Mestrado em Energia na Agricultura, Universidade Estadual do Oeste do Paraná, Cascavel-PR.

${ }^{7}$ Mestrado em Energia na Agricultura, Universidade Estadual do Oeste do Paraná, Cascavel-PR.

Palavras-chave: Biocombustíveis, Crambe abyssinica Hochst, culturas energéticas.

\section{Resumo}

A produção brasileira de biodiesel esta difundida e baseada em culturas anuais, com poucas alternativas para outono e inverno a fim de se manter continua a produção deste biocombustível. Neste cenário destaca-se a cultura do crambe, com alto teor de lipídico em seus grãos e óleo apresentando características importantes que se enquadram nos padrões nacionais de produção e comercialização de biodiesel. O presente trabalho visa trazer um apanhado de informações técnico-cientificas sobre manejo, produção e processamento do crambe, deve se lembrar que a disponibilidade de informações sobre cultura em literatura é escassa, havendo a necessidade de pesquisas a serem desenvolvidas visando estruturar a cultura no Brasil.

\section{Introdução}

Segundo Santos et al. (2012), apesar de grande parte da energia utilizada no mundo ser proveniente de fontes não renováveis, a busca crescente por outras fontes de energia, tem 
levado a pesquisa de diversas culturas que possam ser utilizadas com a finalidade de produção de biodiesel. Mesmo com a grande diversidade de culturas oleaginosas presentes no Brasil, a maior parte da produção de biodiesel ainda é suprida pelo óleo de soja (SILVA et al., 2009).

Nacionalmente, a produção deste combustível está difundida com base em culturas anuais, de ciclo primavera/verão, com poucas alternativas para o outono/inverno a fim de manter-se contínua a produção de biodiesel, além da rotação de culturas (JASPER et al., 2010).

O crambe (Crambe abyssinica Hochst.) é pertencente da família das crucíferas e oriundo da zona mediterrânea. Apresenta grande potencial para produção de óleo destinado a fabricação de biodiesel principalmente em estações e períodos de temperaturas baixas. Assim como o nabo forrageiro (Raphanus sativus), o crambe é uma cultura que apresenta ciclo anual com grande potencial de cultivo na região centro-oeste do Brasil (FALASCA et al., 2010; SOUZA et al., 2009).

Existem pesquisas com relação à base de produtividade da cultura do crambe, porém ainda nota-se certa escassez em trabalhos que buscam definições de tratos culturais e técnicas especifica de manejo. O presente trabalho visa trazer de forma clara informações técnicas de produção, beneficiamento e produção da cultura do crambe.

\section{CARACTERISTICAS BOTÂNICAS}

É uma planta herbácea anual, apresentando por volta de um metro de altura, cuja haste ramifica-se próxima ao solo formando trinta ou mais galhos, que subsequentemente se ramificam, formando galhos terciários (DESAI et al., 1997).

Suas folhas (Figura 1) são ovais e assimétricas com lâmina foliar de aproximadamente $10 \mathrm{~cm}$ de comprimento e $7 \mathrm{~cm}$ de largura, com sua superfície lisa. Seu pecíolo apresenta aproximadamente $20 \mathrm{~cm}$ de comprimento e é pubescente (OPLINGER et al., 2008). 


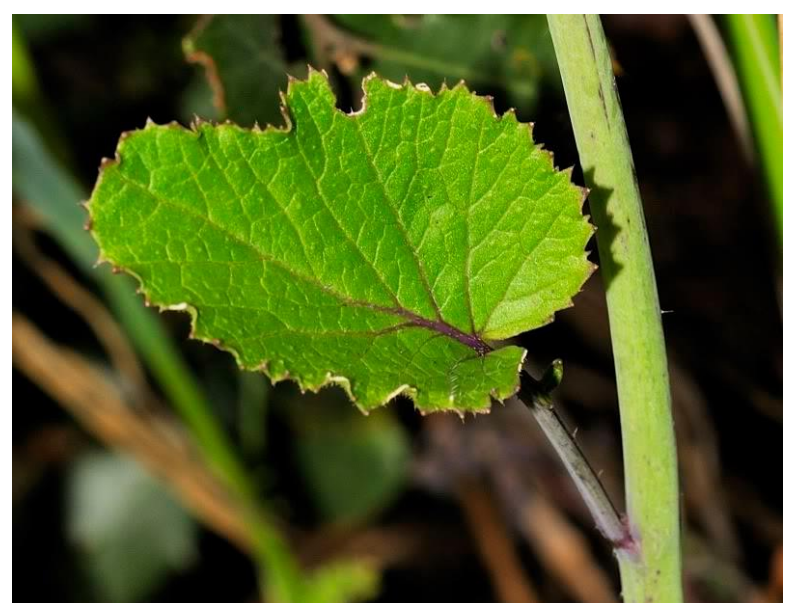

FIGURA 1: Folha de Crambe hispânica L. (Fonte: Blog Dias com árvores 2013)

As sementes presentes são albuminosas, ortodoxas, do tipo cariopse e tem seu eixo embrionário curvo, com presença de plúmula protegida por uma fina cobertura mucilaginosa (SOUZA et al., 2009; CRUCIFERAE, 1985). As sementes também apresentam elevado potencial lubrificante e teor de óleo, com valores entre 30 e $45 \%$ da semente (TOEBE, 2010). Permanecendo aderido as sementes mesmo após a colheita, o pericarpo representa em torno de $30 \%$ do peso total dos frutos, com elevado conteúdo de lignina e de celulose (GASTALDI et al., 1998).

\section{MANEJO DA CULTURA DO CRAMBE}

\section{Condições de plantio}

Segundo Toebe et al. (2010), é uma importante cultura, tolerante ao frio sendo que a planta é capaz de resistir sem maiores danos a temperaturas de até -6,0 ${ }^{\circ} \mathrm{C}$ (PILAU et al., 2011), e requer temperaturas entre $15^{\circ} \mathrm{C}$ e $25^{\circ} \mathrm{C}$ em seu período vegetativo (FALASCA et al., 2010).

No Brasil, o cultivo do crambe se iniciou na década de 90, nos estados do Mato Grosso do Sul, no sul e no sudeste do país. Devido sua grande tolerância a secas e seu curto ciclo de cultivo apresenta certa vantagem diante de outras oleaginosas, além de seu cultivo mecanizado e custos de produção relativamente baixos (ONOREVOLI, 2012). Segundo Plein et al. (2010), o crambe apresenta boa adaptação, rusticidade, precocidade e bom potencial produtivo. Ainda é considerada uma cultura de inverno e, portanto, pode-se caracterizar como alternativa para ser plantada após a colheita da soja, no período que compreende entre março e abril. 
Ainda segundo Laghetti (1995), por ser um vegetal muito robusto pode suportar desde geadas típicas do sul do país até climas úmidos e quentes como os do centro-oeste do país.

Para o plantio, produtividades aceitáveis são obtidas com espaçamentos que variam de 15 e $70 \mathrm{~cm}$, entretanto, recomendam-se solos com linhas entre 15 e $30 \mathrm{~cm}$, apresentando assim maior produtividade. $\mathrm{O}$ crambe quando cultivado com espaçamentos maiores que 80 cm apresenta acamamento, dificultando a colheita (KNIGHTS, 2002).

\section{Solo e Adubação}

O sistema radicular do crambe é ligeiramente profundo, onde a cultura é considerada interessante se visando à reciclagem de nutrientes. No entanto, apresenta certa exigência quanto à acidez presente no solo. Visando um desenvolvimento adequado, o solo deve apresentar de boa a alta fertilidade, sendo que a camada de 0 a $20 \mathrm{~cm}$ deve ser corrigida e de 20 a $40 \mathrm{~cm}$ deve conter baixa saturação de $\mathrm{Al}^{3+}$ (PITOL et al., 2010).

$\mathrm{Na}$ implementação da cultura, busca-se escolher solos profundos, férteis ou corrigidos corretamente, apresentando teores de argila superior a 20\% quando eutróficos e $25 \%$ quando distróficos (BROCH e ROSCOE, 2010).

Os fertilizantes são insumos com maior peso para a maioria das plantas, sendo que seu uso eficiente é fundamental para garantir boa produtividade e rentabilidade. Adubação nitrogenada pode exercer influência na duração dos sub-períodos de desenvolvimento e alterações de filocrono e plastocrono (TOEBE et al., 2010). Rogério et. al. (2012), comprovou com experimentação que adubação fosfatada em quantidades específicas promove melhor desenvolvimento radicular, garante uma arrancada vigorosa, estimula o florescimento e ajuda a formação das sementes.

Assim como a colza e a canola (Brassica napus L), o crambe responde de forma semelhante à fertilidade do solo (Knights, 2002). O emprego de potássio no solo influenciou a absorção pela planta, ou seja, maiores taxas de potássio no solo conduzem a maior absorção de nutrientes, e consequente desenvolvimento da planta (SANTOS et al., 2012).

Dejetos de outras cadeias agroindustriais podem ser utilizados na fertirrigação da cultura do crambe. Os dejetos provenientes de suínos são altamente concentrados, com valores médios de matéria orgânica DBO 12.000 e DQO 21.000 mg/l (MEDRI, 2004). Segundo a EMBRAPA (1997), o dejeto de suíno possui $2,33 \mathrm{~kg} / \mathrm{m}^{3}$ de Nitrogênio, $0,66 \mathrm{~kg} / \mathrm{m}^{3}$ de fósforo e $0,90 \mathrm{~kg} / \mathrm{m}^{3}$ de potássio, justificando desta maneira experimentos na cultura do 
crambe com utilização de água residuária de suinocultura por apresentar uma grande concentração de nitrogênio.

A vinhaça também pode promover melhoria na fertilidade do solo a partir de alguns efeitos como a elevação do $\mathrm{pH}$, aumento da capacidade de troca catiônica e aumento da capacidade de retenção de água, alem de melhoria da estrutura física do solo. A vinhaça deve ser vista, também, como agente do aumento da população e atividade microbiana no solo (SILVA et al., 2007).

\section{Colheita do crambe}

Como característica da cultura nota-se sua precocidade, florescendo aos 35 dias apresentando grãos maduros entre 90 a 100 dias e alta produtividade, podendo atingir 2.500 kg/ha em sementes (JASPER et al., 2010; FALASCA et al., 2010).

Ao se aproximar do término do ciclo da cultura, as folhas tendem a secar e consequentemente cair. Em alguns dias após, a coloração das vagens e de pequenos ramos começa a amarelar, a partir disso chega-se ao ponto de colheita. Após este período, o crambe pode ser colhido com colhedora automotriz comum, apenas realizando alguns ajustes em sua peneira. Seguindo então para o processo de limpeza e posterior secagem dos grãos (JASPER, 2009).

A realização da colheita das sementes ao atingir-se o ponto de maturidade fisiológica diminui a exposição da mesma as ações de temperatura, umidade relativa do ar, alguns insetos e patógenos que podem vir a causar danos aos grãos (OLIVA, 2010).

Segundo trabalho de Jasper et al. (2010), a cultura do crambe apresenta menor custo de produção, desde seu plantio e colheita até seu pré-beneficiamento, do que outras fontes oleaginosas como a canola, girassol e soja.

Realizando a análise energética da cultura do crambe comprovou-se que a energia líquida para produção foi de 37.153,67 MJ/ha, resultando numa eficiência de 9,98, desta forma, comprova-se que a cada unidade de energia aplicada na produção de crambe, a conversão é de 8,98 unidades de energia. A capacidade energética foi de 38,96, ao passo que, para cada unidade usada de energia fóssil, o retorno é de 37,96 unidades de energia na produção da cultura de crambe.

\section{PROCESSAMENTO DOS GRÃOS}


O processamento do crambe é muito parecido ao de outras culturas oleaginosas. A extração do óleo pode ser realizada através de diversos métodos, dentre os principais a prensagem mecânica e extração por solventes. No entanto, antes do processo de extração nos grãos, é necessário realizar o descascamento, limpeza, secagem, desintegração, floculação e condicionamento (CARVALHO, 2011).

A extração mecânica é considerada a etapa onde ocorre a separação de líquidos e de sólidos através do emprego de forças de compressão, tendo como principal resultado o mínimo resíduo de óleo presente na torta (BRENNAN et al., 1990). Para o emprego da extração mecânica utilizam-se equipamentos rudimentares como: prensas hidráulicas, que são mais utilizadas em instalações menores que não justificam a prensagem hidráulica contínua; e prensas contínuas tipo "expeller" que possuem maior capacidade, requerendo menores investimentos e mão de obra (CARVALHO, 2011).

O procedimento de extração por solvente é uma operação onde ocorre transferência de massa e é muito empregado na indústria de alimentos, onde a penetração do solvente na semente que é previamente triturada promove remoção do óleo através da difusão. Em processos de prensagem hidráulica, a torta ainda contém cerca de $6 \%$ de óleo residual, enquanto em processos com extração por solvente esta quantidade é inferior a $1 \%$ (TANDY, 1991).

Existem ainda algumas outras formas de separação entre o óleo e a torta, como: processos de destilação, muito semelhante ao uso de solventes; extração supercrítica com emprego de $\mathrm{CO}_{2}$ como solvente; e por fervura caseira (BERNARDO-GIL et al., 2002).

\section{ÓLEO DE CRAMBE E PRODUÇÃO DE BIODIESEL}

O óleo de crambe possui elevado teor de ácidos graxos de alto peso molecular, e a predominância ocorrente é do ácido erúcico, seguido então do ácido oleico, tornando o óleo impróprio para consumo humano, sendo uma interessante alternativa para a produção de biodiesel (LAGHETTI, 1995; LAZZERI et al., 1997). O perfil de ácidos graxos pode ser visualizado na Tabela 1.

TABELA 1: Parâmetros e Técnicas Analíticas Utilizadas.

\begin{tabular}{|l|c|c|}
\hline \multicolumn{1}{|c|}{ Ácido } & Símbolo & \% \\
\hline Palmítico & C16:0 & - \\
\hline Esteárico & C18:0 & 1,1 \\
\hline Oléico & C18:1 & 17,8 \\
\hline Linoléico & C18:2 & 6,1 \\
\hline
\end{tabular}




\begin{tabular}{|l|l|c|}
\hline Linolênico & C18:3 & 2,8 \\
\hline Araquídico & C20:0 & 1,7 \\
\hline Gadoléico & C20:1 & 6,7 \\
\hline Behênico & C22:0 & 3,7 \\
\hline Erúcico & C22:1 & 56,7 \\
\hline Lignocérico & C24:0 & - \\
\hline Nervônico & C24:1 & - \\
\hline
\end{tabular}

Fonte: Silva et al. (2009).

O óleo de crambe apresenta índices de acidez superior a $1 \mathrm{mg} \mathrm{KOH/g}$, devendo então ser neutralizado se usado na produção de biodiesel. Pela alta concentração de ácido erúcico, e este possuir como característica a alta tolerância à temperaturas elevadas, pode ser utilizado como óleo de transmissão (ONOREVOLI, 2012).

Segundo trabalho de Enerbio et al. (2011), como o crambe é uma cultura que não exige demasiados cuidados e possui elevada produtividade, oferece grande viabilidade econômica na produção de biodiesel. Ainda garante que a transesterificação com etanol apresenta resultados satisfatórios proporcionando assim uma rota totalmente renovável.

O biodiesel produzido a partir do óleo de crambe pode trazer diversas vantagens, pois este óleo apresenta baixo ponto de fusão $\left(-12^{\circ} \mathrm{C}\right)$, e alta estabilidade oxidativa, sendo assim uma alternativa muito interessante para utilização com misturas de matérias-primas que apresentem qualidade inferior (ROSCOE et al., 2010). Segundo Wazilewski et al. (a. 2012), o biodiesel produzido do óleo de crambe é mostrado como mais estável do que o obtido a partir do óleo de soja. Ainda afirma que o biodiesel de crambe estabiliza as alterações viscosimétricas de biodiesel de soja quando eles são misturados em diferentes proporções.

As vantagens de óleos vegetais não comestíveis como o óleo de crambe, são portabilidade natural do líquido, pronta disponibilidade, renovabilidade, poder calorifico superior, menor teor de enxofre e menor biodegradabilidade (NO, 2011). Em Pesquisa de Wazilewski et al. (2012b), o biodiesel produzido a partir do óleo de crambe possui elevada estabilidade ao stress térmico e atende às normativas quanto ao tempo mínimo exigido para o período de indução, além disso, a viscosidade cinemática do biodiesel metílico de crambe é pouco elevada, porem apresenta-se dentro dos limites máximos aceitos pelas normativas. $\mathrm{O}$ ponto de fulgor e densidade também se encontraram dentro das faixas ótimas.

Ainda segundo Silveira et al. (2012), o biodiesel de crambe produzido por rota metílica garante uma boa conversão do óleo com diversas condições empregadas, chegando à conclusão que a catálise alcalina é a melhor se empregada para produção de biodiesel, 
proporcionando melhores rendimentos, atendendo às especificações da legislação brasileira para o seu uso e comercialização como combustível.

Colodetti et al. (2012), cita a importância do crambe na produção de biodiesel, sendo que a maioria dos óleos utilizados para este fim são provenientes de culturas anuais, principalmente de culturas com ciclos de primavera e verão, faltando opções nas outras estações que permitam a continuidade da produção de biodiesel e utilização na indústria.

Além da produção de biodiesel, o óleo obtido a partir dos grãos de crambe pode ser usado como lubrificante industrial, e na fabricação de borracha sintética, pelo seu alto conteúdo em ácido erúcico (50 a 60\% do óleo). Ainda se compreende a utilização deste óleo na fabricação de plásticos, adesivos e isolação elétrica (SANTOS et al., 2012).

\section{Conclusão}

Com o crescente interesse no desenvolvimento e produção de combustíveis alternativos a cultura do crambe, antes basicamente utilizado na produção de forragem, apresenta-se em expansão de cultivo, incentivando a possibilidade de interação no manejo da cultura e obtenção do óleo visando à produção de biodiesel.

O desenvolvimento da cadeia produtiva do crambe pode proporcionar diversos benefícios sociais, econômicos e ambientais, além de ser uma saída para diversificação da matriz energética, com potencial para produção de biocombustíveis, no entanto, mais informações técnicas e pesquisas devem ser desenvolvidas visando estruturar a cultura no Brasil. 


\section{Referências}

1. AMERICAN PUBLIC HEALTH ASSOCIATION - APHA, AWWA, WEF. Standard methods for the examination of water and wastewater. 20 ed. Washington: American Public Health Association, 1998.

2. BERNARDO-GIL, M.; RIBEIRO, G.; ESQUÍVEL, M.M. Produção de extratos para a indústria alimentar: uso de fluídos supercríticos. Boletim de Biotecnologia, POR, v.73, p. 14-21, 2002.

3. BRENNAN, J. G.; BUTters, J. R.; COWELl, N. D.; LILlEY, A. E. V. Food engineering operations. Linton Road, England: Elsevier Applied Science, 1990.

4. BROCK, J.; NOGUEIRA, M. R.; ZAKRZEVSKI, C.; et al. Determinação Experimental da Viscosidade e Condutividade Térmica de Óleos Vegetais. Ciência e Tecnologia de Alimentos, Campinas, 28(3): 564-570. 2008.

5. BROCH, D. L.; ROSCOE, R. Fertilidade do solo, adubação e nutrição do crambe. In: FUNDAÇÂO MS. Tecnologia e produção: crambe. Maracajú: FUNDAÇÃO MS, v. 1, p. 22-36, 2010.

6. CARVAlHO, T. C. de; SILVA, C. L. da, Redução da Quantidade de Vinhaça Através da Evaporação. Periódico Fórum Ambiental da Alta Paulista, vol.4, 2010.

7. CARVAlHO, C.O. de; Comparação entre Métodos de Extração do Óleo de Mauritia Flexuosa L.F. (Arecaceae - Buriti) para o Uso Sustentável na Reserva de Desenvolvimento Tupé: Rendimento e Atividade Antimicrobiana. Dissertação (Mestrado), Pós-Graduação em Biotecnologia e Recursos Naturais. UEA. Manaus - AM. 2011.

8. COLODETTI, T.V.; MARTINS, L.D.; et al. Crambe: Aspectos Gerais da Produção Agrícola. Enciclopédia Biosfera, Centro Cientifico Conhecer, Goiania, v.8, n.14, pag. 258-269. 2012.

9. DESAI, B. B.; KOTECHA, P.M.; SALUNKHE, D. K. Seeds handbook: biology, production processing and storage. New York: Marcel Dekker, 627 p. 1997.

10. Embrapa - Suínos e Aves. Ano 7 Bipers $\mathrm{N}^{\circ} 11$ Março/1998. Disponível em: <http://www.cnpsa.embrapa.br /> Acesso em: out 2012.

11. EMPRESA BRASILEIRA DE PESQUISA AGROPECUÁRIA - EMBRAPA. Centro Nacional de Pesquisa de Solos. Sistema brasileiro de classificação de solos. 2.ed. Rio de Janeiro, 2006. 306p.

12. ENERBIO, M.F.M.; ENERBIO, A.P.B.B.; et al. Produção de Biodiesel a Partir do Óleo de Crambe (Crambe abyssinica) Utilizando Álcool Etílico. 2011. Disponível em: < http://www.enerbio.ind.br/wp-content/uploads/2011/05/a5_535-Producao-de-Biodiesela-Partir-de-Oleo-de-Crambe.pdf> Acesso: maio/2013.

13. FALASCA, S. L.; LAMAS, M. C.; CARBALlO, S. M.; ANSCHAU, A. Crambe abyssinica: An almost unknown crop with a promissory future to produce biodiesel in Argentina. International Journal of Hydrogen Energy, v.35, p.5808-5812, 2010.

14. GASTALDI, G. et al. Characterization and properties of cellulose isolated from the Crambe abyssinica hull. Industrial Crops and Products, Amsterdam, v. 8, n. 3, p. 205-218, set. 1998.

15. GRANJEIRO, R. V. T. Caracterização da água de lavagem proveniente da purificação do biodiesel. Dissertação (Mestrado), Universidade Federal da Paraíba, Programa de Pósgraduação em Química, João Pessoa - PB. 2009.

16. INSTITUTO ADOLFO LUTZ. Normas Analíticas do Instituto Adolfo Lutz. v. 1: Métodos químicos e físicos para análise de alimentos, 3. ed. São Paulo: IMESP, pág. 2526. 1985. 
17. JASPER, S.P. Cultura do Crambe (Crambe abyssinica hochst): Avaliação Energética, de Custo de Produção e Produtividade em Sistema de Plantio Direto. Tese (Doutorado), Faculdade de Ciências Agronômicas UNESP. Botucatu - SP. 2009.

18. JASPER, S. P.; BIAGGIONI, M. A. M.; SILVA, P. R. A. Comparação do Custo de Produção do Crambe (Crambe abyssinica Hochst) com Outras Culturas Oleaginosas em Sistema de Plantio Direto. Revista Energia na Agricultura, Botucatu, vol. 25, n.4, p.141153. 2010.

19. Laghetti G.; et al. Yield and oil quality in selected lines of Crambe abyssinica grow in Italy. Industrial crops and products, Itália. 1995.

20. LAZZERI, L.; DE MATTEI, F.; et al. Crambe oil - a potencial new hidraulic oil and quenchant. Industrial Lubrication and Tribology. Vol.49, n.2, pag. 71-77. 1997.

21. MEDRI, W.; MEDRI, V. Otimização de sistemas de lagoas de estabilização para tratamento de dejetos suínos. Semina: Ciências Exatas e Tecnológicas, Londrina, v.25, p.203-2012, 2004.

22. NO, S.; Inedible vegetable oils and their derivatives for alternative diesel fuels in CI engines: A review. Renewable and Sustainable Energy Reviews, n.15, pág. 131-149. 2011.

23. OLIVA, A.C.E. de, Qualidade de Sementes de Crambe Submetidas a Métodos de Secagem e Períodos de Armazenamento. Dissertação (Mestrado), Faculdade de Ciências Agronômicas. UNESP, Botucatu - SP. 2010.

24. ONOREVOLI, B. Estudo do Crambe abyssinica como Fonte de Matérias Primas oleaginosas: óleo vegetal, ésteres metílicos e bio-óleo. Dissertação (Mestrado), Universidade Federal do Rio Grande do Sul. Porto Alegre -RS. 2012.

25. OPLINGER, E. S.; et al. Crambe: alternative field crops manual. Disponível em: <http://www.hort.purdue.edu/newcrop/afcm/crambe.html >. Acesso em: maio/2013.

26. PILAU, F. G.; BATTISTI, R.; SOMAVILLA, L.; SCHWERZ, L. Temperatura basal, duração do ciclo e constante térmica para a cultura do crambe. Agrometeorologia. Bragantia, Campinas, v. 70, n. 4, p.958-964, 2011.

27. PITOL, C.; BROCH, D. L.; ROSCOE, R. Tecnologia e Produção: Crambe 2010. Maracaju: Fundação MS, 60p. 2010.

28. PLEIN, G.S.; FAVARO, S.P.; et al. Caracterização da Fração Lipídica em Sementes de Crambe Armazenas com e sem Casca. IV Congresso Brasileiro de Mamona e I Simpósio Internacional de Oleaginosas Energéticas. João Pessoa - PB. 2010.

29. ROSCOE, R.; BROCH, D.L.; NERY, W.S.L. Análise de Sensibilidade dos Modelos Agrícolas e Industrial de Utilização do Óleo de Crambe na Cadeia Produtiva de Biodiesel em Mato Grosso do Sul. IV Congresso Brasileiro de Mamona e I Simpósio Internacional de Oleaginosas Energéticas, João Pessoa - PB. 2010.

30. SANTOS, J. I.; ROGÉRIO, F.; MIGLIAVACCA, R. A.; et al. Efeito da Adubação Potássica na Cultura do Crambe. Biosci. J., Uberlândia, v. 28, n. 3, p. 346-350. 2012.

31. SCHULTZ, G. Boas práticas ambientais na suinocultura. Porto Alegre, RS: SEBRAE/RS, 2007.

32. SILVA, M. A. S.; GRIEBELER, N. P.; BORGES, L. C. Uso de vinhaça e impactos nas propriedades do solo e lençol freático. Revista Brasileira de Engenharia Agrícola e Ambiental, v.11, n.1, p.108-114. 2007.

33. SILVA, P. R.; MONTANHER, A. F.; ADÃO, D. C.; ZAGONEL, G. F.; et al. Caracterização físico-química de óleo e biodiesel metílico de crambe. $3^{\circ}$ Congresso da Rede Brasileira de Tecnologia de Biodiesel - RBTB. Brasília - DF. 2009.

34. SILVEIRA, E.V.; ALEXANDRE, E.C.F.; et al. Efeito da catálise ácida alcalina na produção e propriedades físico-químicas do biodiesel metílico de crambe (Crambe 
abyssinica Hochst). I Congresso de Pesquisa e Pós-graduação do Campus Rio Verde do IFGoiano. 2012.

35. SOUZA, A. D. V.; FÁVARO, S. P.; ÍTAVO, L. C.; ROSCOE, R. Caracterização química de sementes e tortas de pinhão manso, nabo-forrageiro e crambe. Pesquisa Agropecuária Brasileira, v.44, p.1328-1335, 2009.

36. TANDY, D. C. Oilseed extraction. In: WAN, P. J. Introduction to fats and oils technology. Champaign, Illinois: American il Chemists' Society, 1991.

37. TOEBE, M.; BRUM, B.; LOPES, S. J.; et al. Estimativa da área foliar de Crambe abyssinica por discos foliares e por fotos digitais. Ciência Rural, Santa Maria, v.40, n.2, p.475-478. 2010.

38. WAZILEWSKI, W.T.; BARICCATTI, R.A.; et al. Study ofthe methyl crambe (Crambe abyssinica Hochst) and soybean biodiesel oxidative stability. Insdustrial Crops and Products, n.43, pág. 207-212. 2012a.

39. WAZILEWSKI, W.T.; ROSA, H.A.; et al. Avaliação de Propriedades Físico-químicas do Biodiesel Metílico de Óleo de Crambe abyssinica hochst. Jornal of Agronomic Science, v.1, n.1, pag. 187-195. 2012b. 